\title{
18
}

\section{Evolution of an Integrated 1D/2D Modeling Package for Urban Drainage}

\author{
Thomas E. Barnard, Anthony W. Kuch, Geoffrey R. \\ Thompson, Sudesh Mudaliar and Brett C. Phillips
}

Recent flooding events in North America have revealed deficiencies in existing stormwater infrastructure and management practices. The development of effective and efficient designs requires a comprehensive understanding of flooding in urban areas and complex open channel and overland flow systems. Traditional one dimensional (1D) models are used to simulate flow in river channels and gravity collection networks but are inadequate for simulating phenomenon such as significant street flooding and overbank flow in flood plains that occurs during extreme events. 1D/2D and $2 \mathrm{D}$ models have begun to be used but their complexity, cost and significant data requirements have limited their application.

The availability of high quality digital terrain models (DTMs), the increased power of desktop computers as well as the need for more realistic simulation of flooding have all contributed to the adoption of 2D models for flood plain mapping and the analysis of overland flows. xpswmm is a comprehensive 1D hydraulics and hydrology modeling package for stormwater and wastewater systems. xpswmm2D was created by coupling the 1D capabilities of the xpswmm software package with the 2D hydrodynamic model TUFLOW. An additional feature was created to dynamically link 1D nodes and links to 2D cells in a single model.

Barnard, T., A. Kuch, G.R. Thompson, S. Mudaliar and B.C. Phillips. 2007. "Evolution of an Integrated 1D/2D Modeling Package for Urban Drainage." Journal of Water Management Modeling R227-18. doi: 10.14796/JWMM.R227-18.

(C) CHI 2007 www.chijournal.org ISSN: 2292-6062 (Formerly in Contemporary Modeling of Urban Water Systems. ISBN: 0-9736716-3-7) 
New technologies were required to create the integrated package for both the model building and the presentation of results. For example, the incorporation of a DTM into the hydrodynamic model allows the generation of the 2D grid elevations, automatic creation of cross sections and the results to be displayed in perspective views. New modeling objects were developed to represent head and flow boundaries, $1 \mathrm{D} / 2 \mathrm{D}$ interfaces, breaklines, catchments and 2D domains.

A variety of case studies are presented that demonstrate the new combined $1 \mathrm{D} / 2 \mathrm{D}$ hydraulic routing including a comparison of $1 \mathrm{D}, 1 \mathrm{D} / 2 \mathrm{D}$ and $2 \mathrm{D}$ results. This chapter concludes that combined $1 \mathrm{D} / 2 \mathrm{D}$ modeling in xpswmm2D offers modelers increased capabilities to investigate the performance of urban drainage systems and of urban waterways and floodplains during extreme events.

\subsection{Background}

\subsubsection{The Need for Drainage System Models}

Engineers, planners and managers use numerical models to simulate the transformation of rainfall to runoff and to follow its complex path across land, into collection and conveyance systems and ultimately to streams, rivers, or other receiving bodies. Models simulate the performance of collection systems and natural channels under a variety of storm events, antecedent conditions, physical upgrades, and future changes in land use. Results of these models in terms of extent and duration of flows, velocities and water surface elevations are used in:

- flood plain mapping;

- planning and design of infrastructure;

- operation of collection and conveyance systems;

- evacuation plans;

- mitigation of urban flooding; and

- assessment of augmentation alternatives.

The United States Federal Emergency Management Authority (FEMA) maintains over 90,000 maps delineating flood plains. However, $70 \%$ of these maps are more than 10 years old and many of the flood plains were hand-drawn and are difficult to update. Development over time has generally rendered many of these maps inaccurate and obsolete (OIG, 2005). FEMA 
also annually receives over 10,000 requests for letters of map revision and letters of map amendments that it must respond to within 60 days.

FEMA has implemented a map modernization program (FEMA, 2001) and is employing existing and exploring emerging technologies for each component of the modernized flood map. One of the objectives is to automate the hydrologic and hydraulic process. As an example of the scope of this program, the state of Georgia is managing a six-year, US\$18.2 million program to create and update flood insurance rate maps (FIRMs) for all 159 counties and 531 communities in the state by 2009. Nearly 7,000 digital FIRMs are expected to be produced (DePue, 2005).

\subsubsection{D Models for Drainage System}

Numerous public domain and commercial software packages are available to assist modelers in constructing numerical models for their catchments and conveyance systems. Table 18.1 presents a summary of the typical models using the categories defined in Haestad Methods et al. (2003). These are the same categories used by FEMA in its lists of numerical models accepted for the National Flood Insurance Program (Bello, 2004).

Table 18.1 Classification of models used in urban drainage and flooding analysis.

\begin{tabular}{|c|c|c|}
\hline Type & Description & Examples \\
\hline $\begin{array}{l}1 \mathrm{D} \text { gradually varied } \\
\text { steady flow }\end{array}$ & $\begin{array}{l}\text { Constant discharge, small changes in depth and } \\
\text { velocity along channel }\end{array}$ & HEC-RAS \\
\hline Quasi-unsteady flow & $\begin{array}{l}\text { Hydrologic routing procedures used to account for } \\
\text { storage }\end{array}$ & $\begin{array}{l}\text { HEC-HMS } \\
\text { TR20 }\end{array}$ \\
\hline $\begin{array}{l}1 \mathrm{D} \text { gradually varied } \\
\text { unsteady flow }\end{array}$ & $\begin{array}{l}\text { Momentum and continuity equations (St Venant) } \\
\text { used. Changes in velocity and depth with time and } \\
\text { distance resulting in acceleration }\end{array}$ & $\begin{array}{l}\text { EPA SWMM } \\
\text { xpswmm }\end{array}$ \\
\hline $\begin{array}{l}\text { Quasi-2D unsteady } \\
\text { flow }\end{array}$ & $\begin{array}{l}\text { Web of links and nodes with pre-defined flow paths } \\
\text { and accounting for storage at specified locations }\end{array}$ & $\begin{array}{l}\text { EPA SWMM } \\
\text { xpswmm }\end{array}$ \\
\hline $\begin{array}{l}\text { 2D gradually varied, } \\
\text { unsteady flow }\end{array}$ & $\begin{array}{l}\text { St Venant equations solved in } 2 \text { dimension, depth } \\
\text { averaged condition }\end{array}$ & $\begin{array}{l}\text { RMA2 } \\
\text { FESWMS-2D } \\
\text { TUFLOW }\end{array}$ \\
\hline 1D/2D linked & $\begin{array}{l}\text { 1D used for pipes channels and other defined flow } \\
\text { structures, dynamically linked to 2D }\end{array}$ & $\begin{array}{l}\text { xpswmm2D } \\
\text { SOBEK }\end{array}$ \\
\hline
\end{tabular}


$1 D$ gradually varied steady flow models are the most commonly used type for flood insurance rate map studies. They are typically run at the peak discharge expected from the design storm event. These models assume that:

- peak discharge is not affected by storage in the river system or that storage has been addressed in a separate study using a hydrologic model; and

- the peak discharge and stage occur simultaneously in each reach.

Quasi-unsteady flow models are hydrologic routing procedures. They are used when the effect of storage must be addressed or when the change in discharge caused by the timing of additional flow from tributaries is analyzed.

ID gradually varied unsteady flow models use the momentum and continuity equations (St. Venant equations) to perform a simulation through time and space. These models are appropriate for long stream reaches and long time periods where velocity vectors can be assumed to be approximately parallel to the flow direction. They should be considered if any of the following conditions are present:

- rapid changes in discharge or elevation;

- a complex system where discharge leaves the main channel and then returns at downstream locations;

- a looped depth-discharge relationship exists;

- flood forecasting for major rivers; and

- backwater analysis at major junctions.

Quasi-2D unsteady models are hybrids. They represent attempts to model storage in channels and detention ponds within a 1D web of links and nodes. Flow paths are predefined.

In $2 D$ gradually varied unsteady flow models, the St. Venant equations are solved in the $\mathrm{x}$ and $\mathrm{y}$ dimensions for the depth averaged condition. Fully two-dimensional (2D) solution schemes have been widely used for modeling river and coastal hydraulics, and more recently, have become a viable practical option for modeling floods. As a flood management tool, 2D models are more accurate and produce results that are far more readily accepted and understood by stakeholders. In river flood models, 2D models are required (Haestad et al, 2003) for:

- flow through and around severe channel restrictions;

- flow in a wide floodplain that is crossed a roadway embankment not perpendicular to the flow direction; 
- low slope, swamp, or wetland areas with poorly defined or no channels; and

- flood elevations throughout the floodplain.

$1 \mathrm{D} / 2 \mathrm{D}$ linked models use $1 \mathrm{D}$ unsteady flow calculations to simulate flow in pipes, channels, culverts and other defined geometries and 2D calculations where the flow is truly two dimensional. The $1 \mathrm{D}$ model is the same link-node system used in traditional models and the 2D domain is defined by a grid of cells with defined slope and roughness. The 1D nodes are linked to a $2 \mathrm{D}$ cell. This linking (or nesting) can be static or dynamic.

Figure 18.1 shows the $1 \mathrm{D}$ and $2 \mathrm{D}$ elements in an urban area where overland flow enters an underground drainage network via grated inlets. During storm events excess flow may pond in the vicinity of an inlet or may move overland to an adjacent inlet. In the drainage network obstructions or inadequate capacity may cause flow to backup or reverse direction.

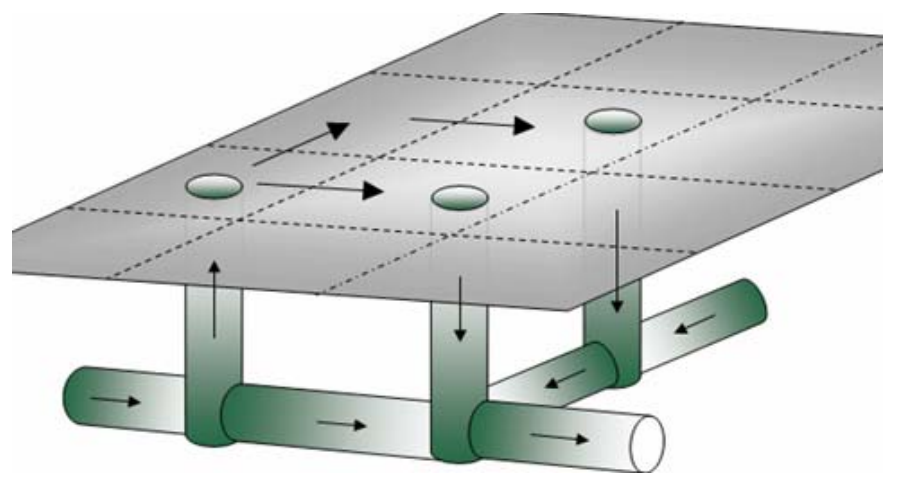

Figure 18.1 Overland flow (2D) and underground drainage network (1D) in a $1 \mathrm{D} / 2 \mathrm{D}$ linked model.

Figure 18.2 shows the 1D and 2D elements in an area drained by an open channel. The channel is represented by the cross sections typical of a 1D unsteady flow model while the flood plain is represented as a grid. Rim elevations of 1D nodes represent the top of the bank of the 1D channel. The surface area of the 1D model is cut out of the 2D grid so that a double accounting of flow volume is not permitted. The water surface in $1 \mathrm{D}$ is allowed to rise vertically in the channel and this same water level is tied to the water level in adjacent water cells (as defined in the 1D/2D interface). The adjacent 1D closed pipe network has manhole rim elevations tied to the 1D grid. 

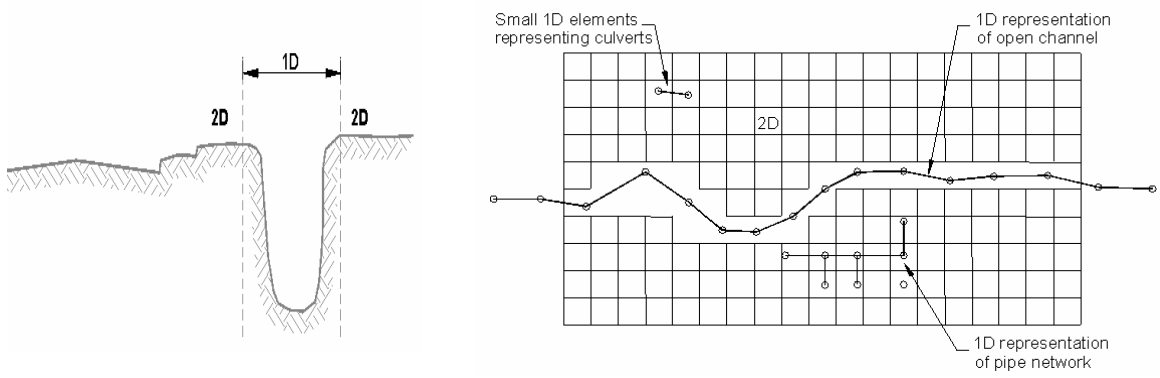

Figure 18.2 Section of channel (left) and plan diagram (right) showing $1 \mathrm{D}$ and $2 \mathrm{D}$ elements in a 1D/2D linked model of both open channel and closed conduits.

\subsubsection{Limitations of 1D Models}

Urban areas have characteristics that make floodplain mapping more difficult than in rural areas (Charteris et al, 2001). These include:

- Increased level of topographic detail;

- Complexity in terrain i.e. roads, curves, inlets;

- Network of inlets and underground conveyance structures; and

- Stormwater management structures such as ponds, levees, pumps and off line storage.

As a result the traditional 1D modeling approach to urban stormwater modeling and floodplain mapping is often inadequate. Key limitations are (Charteris et al, 2001):

Predefinition of Flow Path - A 1D model is developed with branches or channels representing the flow paths and cross sections defining the conveyance characteristics of the branch. However, the flood flow path for a 100 -y event may be quite different to that of a 10-y due to the increased flows and volumes of the larger event. As floodwaters rise during a single flood event, the flow paths may change in length and/or slope and new flow paths may be created.

Transverse Water Slope - In a 1D model, momentum is conserved in 1 direction. There is no accounting for momentum conservation at bends in the river, as a 1D model is only interested in the cross sectionally averaged conveyance characteristics of the section. Additional "form losses" are 
typically applied to account for head losses at the bend, but the water surface across the section is assumed constant. This can lead to problems when the transverse water slope is relatively large, and water levels on the outside of the bend are significantly higher than those on the inside.

Complex 2D Flow Patterns - In complex 2D flow situations the predefinition of the flow path and the inherent difficulties associated with cross sectionally averaged flow and velocity severely limit the application of 1D models. This is a particular problem in areas of flow separation or confluence.

Broad Floodplain Sheet Flow - If the floodplain is broad and flat, a 1D model will evenly distribute the water over the width of the cross section The effect of the flow resistance characteristics (i.e. Manning's n) on this very shallow sheet flow will be quite different to the real world situation where fingers of floodwaters propagate across the floodplain.

Safety Risk Calculations - Often the floodplain manager is interested in safety/risk considerations where the need to identify locations of deep and/or fast flowing water is required. The cross sectionally averaged flow and velocity from a $1 \mathrm{D}$ model cannot be used for this purpose.

Floodplain Mapping - Mapping of the flood extent and depth derived from 1D modeling requires extensive interpretation by the modeler and cartographer. The spatial location of the results may not be geographically referenced but simply identified as a chainage along a branch. This requires considerable interpretation by the cartographer within the chosen GIS environment to geo-reference the results prior to producing flood maps.

Studies have compared 1D and 2D model results for locations in Australia (Phillips et al, 2005 and Charteris et al, 2001) and for urban areas in the United Kingdom (Syme et al, 2004). In addition to overcoming the limitations of 1D models, the 2D models have the advantages of:

- increased detail and accuracy of model definition;

- improved representation of flow regime in complex areas;

- better representation of sheet flow; and

- increased confidence in flooding results due to reduced interpretation required in flood mapping.

\subsubsection{Digital Terrain Models}

Topographic data required for stormwater and flood models includes catchment slope and aspect, flow length, contributing area, drainage divides and stream channel geometry (Grabrecht et al, 2001). Digital terrain models (DTM) are available in three data structures: grid structures (DEM), 
triangulated irregular networks (TIN), or contour based structures. Square grid based DEMs are most widely used because of their computational efficiency. Disadvantages include grid size dependency of certain computed landscape parameters and inability to adjust the grid size to changes in landscape features (ridges, gullies, etc.). TINs overcome these disadvantages to some extent. Contour based data provides a better outline of landscape features and are able to better define drainage lines and overland flow paths. For hydraulic modeling of river channels a TIN data structure is preferred (Tate et al, 2002).

In the United States, $30 \mathrm{~m}$ grids DEMs are available for most of the continental states and $10 \mathrm{~m}$ grids are being developed. However, even $10 \mathrm{~m}$ grids are frequently inadequate for delineating the channel geometry and urban flow paths. Most modeling projects require significant efforts to incorporate elevation data. For example, Tate et al (2002) outlined four methods to digitize a stream thalweg:

1. Reach files from the national hydrologic database;

2. DTM-based delineation using GIS raster analysis;

3. Digital orthophotography; and

4. Land surveys.

The first three involve digital data that can be incorporated in an automated fashion. The collection of field data is the most expensive procedure and typically is used to fill in areas where high resolution is required.

Recent advances in Light Detection and Ranging (LIDAR) (also referred to as aerial laser scanning (ALS) technology) have made high resolution DEMs more widely available and less expensive.

\subsection{Current Technologies}

The program described in this chapter combines the capabilities of two proven hydrologic and hydraulic modeling software products: xpswmm and TUFLOW. A brief overview of these software packages follows

\subsection{1 xpswmm}

xpswmm is a software package for developing link-node and spatially distributed models of stormwater and wastewater flows and water quality. It is used by scientists, engineers and, asset managers to simulate rainfall- 
runoff processes and the performance of engineered conveyance, storage and treatment systems. It also models flow and pollutant transport in natural systems including rivers, lakes, floodplains and groundwater interaction with surface water bodies. It is used to develop link-node and spatially distributed models that are used for the analysis, design and simulation of storm and wastewater systems.

The hydraulic layer in xpswmm solves the complete St. Venant (Dynamic Flow) equations for gradually varied, one dimensional, unsteady flow throughout a drainage network. The solution scheme can handle backwater effects, flow reversals, surcharging, pressure flow, tidal outfalls and interconnected ponds. The model allows for looped networks, multiple outfalls and accounts for storage in conduits. Flow can also be routed using the EXTRAN solution scheme (found in EPA SWMM) or with kinematic or diffusive wave methods.

A distinctive feature of xpswmm is its ability to simultaneously model surface (surcharge and/or overland) flows and subsurface (conduit) flows when stormwater runoff exceeds the hydraulic capacity of the collection system's inlets. The model simulates the local ponding of stormwater as storage and the flow along streets as parallel flow paths. These drainage paths continue downstream until the collection system has sufficient inlet capacity.

Models can be created on a blank x-y grid or over a geo-referenced background. Support is provided for CAD, GIS or any geo-referenced image file as a background.

\subsubsection{TUFLOW}

TUFLOW was selected following an evaluation of several commercial and public domain $1 \mathrm{D} / 2 \mathrm{D}$ modeling packages. It has a computational engine that provides two-dimensional (2D) and one-dimensional (1D) solutions of the free-surface flow equations to simulate flood and tidal wave propagation. TUFLOW was originally the product of a joint research and development project between WBM Pty Ltd and The University of Queensland in Australia that was completed in 1990. The project's objective was to develop a 2D modeling system with dynamic links to a 1D system. Up until 1997 it was used extensively by WBM Pty Ltd for estuarine and coastal studies, with occasional use for flood studies. Since 1997, considerable improvements in flood modeling capabilities and GIS linkages have been developed, resulting in its extensive and wide-ranging application to flood investigations in both Australia and the UK. 
TUFLOW's 2D solution is based on the Stelling finite difference, alternating direction implicit scheme that solves the full 2D free surface shallow water flow (St. Venant) equations. The scheme has been improved to handle upstream controlled flow regimes (i.e. supercritical flow and weir flow), horizontal and vertical flow obstructions (i.e. bridge decks, box culverts, and road embankments) and robust wetting and drying conditions.

\subsection{Development of Integrated Package}

The objective of the project described was to develop an integrated package of tools that would allow modelers to build and run their $1 \mathrm{D}, 1 \mathrm{D} / 2 \mathrm{D}$ or $2 \mathrm{D}$ models in the same graphical user environment. As with the 1D approach, the model uses graphic tools to describe the elements in the network.

\subsubsection{Incorporation of a DTM}

The building of a 2D hydraulic model requires integration with a DTM to obtain cell and point elevations. xpswmm uses a TIN for obtaining elevation data for the 2D grid, the presentation of results and other functions decribed in this chapter. A TIN can be incorporated into a model by any of 3 methods:

1. Direct loading of a TIN file;

2. Creation of a TIN from $x, y, z$ data; and

3. Using the DTM builder tool.

The TIN is loaded via simple dialogs. Once the TIN is loaded the elevation of all points and objects in the model are defined. Additional capabilities allow the user to:

- shade the TIN to graphically show elevation;

- adjust the TIN transparency and show contours;

- use the mouse location to display the elevation on the status bar;

- displays a cross section profile by drawing a polyline;

- automatically calculate the natural channel cross sections for links;

- automatically calculate the node ground elevations and inverts; and

- automatically generate a 2D grid elevation. 


\subsubsection{New Objects}

In order to provide a graphical user interface to the $2 \mathrm{D}$ and $1 \mathrm{D} / 2 \mathrm{D}$ models, new objects had to be created. These correspond to all of the key elements in the numerical calculations of 2D flow and are listed in Table 18.2.

Table 18.2 Objects in 2D and 1D/2D models.

\begin{tabular}{|c|c|c|}
\hline Layer & $\begin{array}{l}\text { Object } \\
\text { type }\end{array}$ & Description or purpose \\
\hline $2 \mathrm{D}$ area extent & polygon & $\begin{array}{l}\text { boundary of } 2 \mathrm{D} \text { model defined, properties include } \\
\text { grid with horizontal and vertical cell size and } \\
\text { orientation }\end{array}$ \\
\hline Active $2 \mathrm{D}$ areas & polygon & areas where $2 \mathrm{D}$ flow can occur \\
\hline Inactive $2 \mathrm{D}$ areas & polygon & $\begin{array}{l}\text { areas where } 2 \mathrm{D} \text { flow cannot occur such as buildings } \\
\text { or raised fill }\end{array}$ \\
\hline 1D/2D interface & polyline & interface between 1D channel and 2D flood plain \\
\hline $1 \mathrm{D} / 2 \mathrm{D}$ connections & polyline & $\begin{array}{l}\text { links the } 1 \mathrm{D} \text { node level to interface between the1D } \\
\text { channel and the } 2 \mathrm{D} \text { floodplain }\end{array}$ \\
\hline 2D head boundary & polyline & time dependent 2D head boundary \\
\hline 2D flow boundary & polyline & time dependent boundary flow boundary \\
\hline Breaklines & polyline & $\begin{array}{l}\text { delineates discontinuities in } 2 \mathrm{D} \text { flow such as ridges or } \\
\text { gullies }\end{array}$ \\
\hline Roughness categories & polygon & $\begin{array}{l}\text { areas of defined land use corresponding to a } \\
\text { Manning's } n\end{array}$ \\
\hline
\end{tabular}

In the xpswmm model environment, tools are available to manage the display (color and line weight) of each object and to toggle the display off/on. The polygons and polylines used to represent these model components can be easily constructed and edited in the graphic environment.

Figures 18.3 and 18.4 show the objects in a $1 \mathrm{D} / 2 \mathrm{D}$ model and demonstrate the model building process. Figure 18.3 shows an open channel flowing from right to left. The channel is defined by links and node as in a conventional 1D model. Note that some of the channel links have bends (defined as vertices). Also, there is an underground drainage network consisting of manholes (links) and pipes (links).

Figure 18.4 shows $2 \mathrm{D}$ objects and $1 \mathrm{D} / 2 \mathrm{D}$ links. The extent of the $2 \mathrm{D}$ model is defined by a boundary. This area is covered by rectangular grid cells with user defined horizontal and vertical size and orientation. Locations where overland flow will not occur such as buildings or raised fill are defined as inactive areas. 


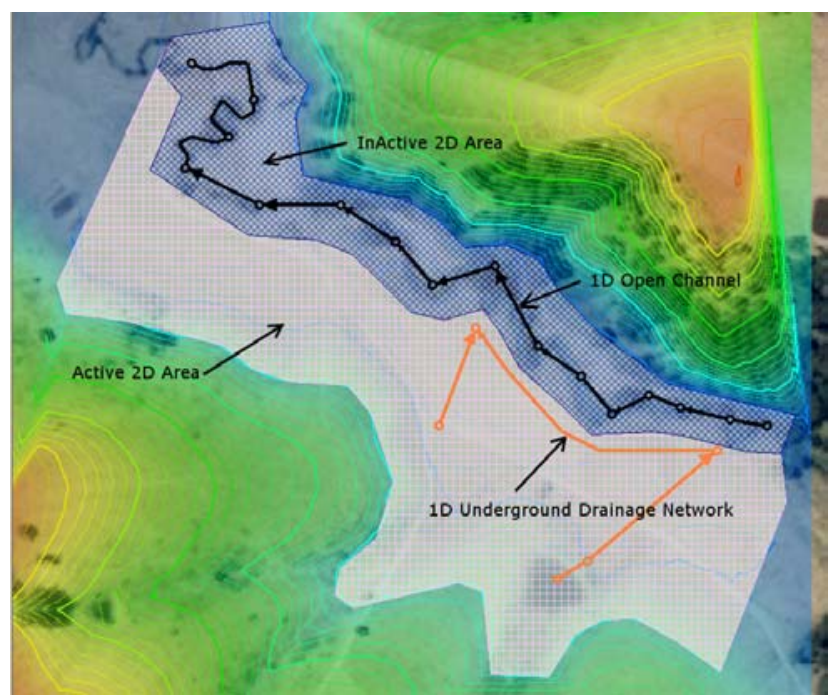

Figure 18.3 1D objects and 2D active areas in 1D/2D model.

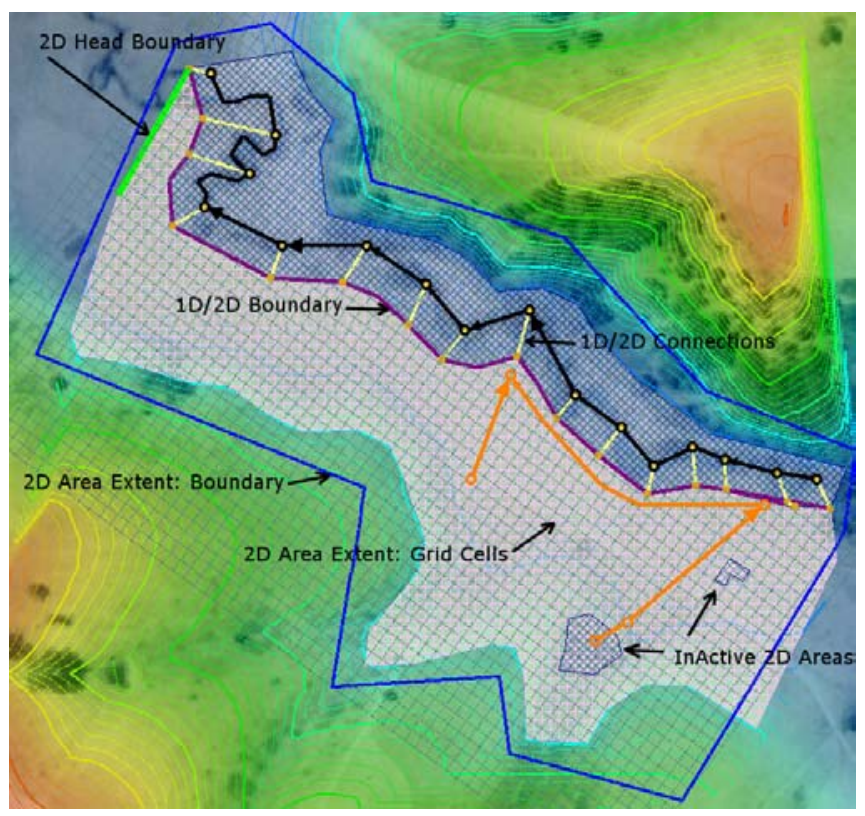

Figure 18.4 2D objects and 1D/2D links in 1D/2D model. 
The 1D/2D interface defines the boundary between the 2D floodplain and the $1 \mathrm{D}$ channel. The $1 \mathrm{D} / 2 \mathrm{D}$ connections define locations where there is water exchange between a $2 \mathrm{D}$ cell and a node in the $1 \mathrm{D}$ network. There is also a shared head level at each connection.

\subsubsection{Model building tools}

Tools were required to assist the modeler in tying elevation data to the model components. The most noteworthy of these is the cross section tool (Figure 18.5). It is used to layout channel cross sections and to generate the shape of the cross section from the TIN.

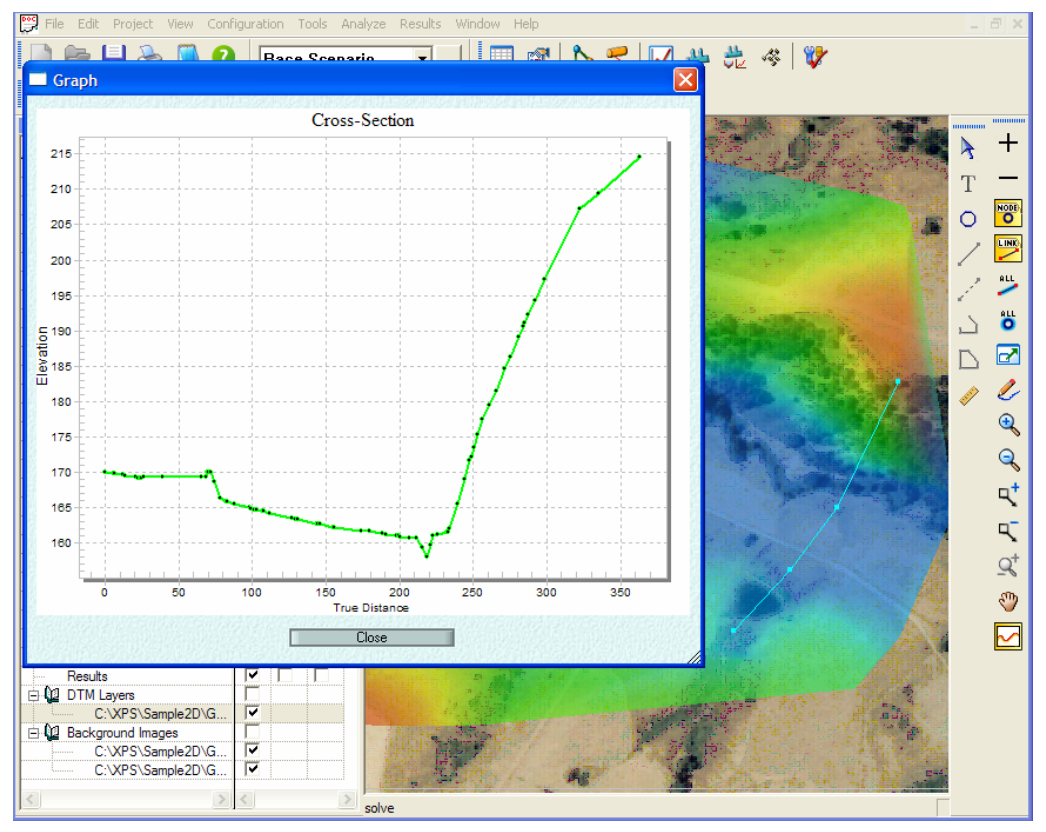

Figure 18.5 Cross section generated from user defined polyline.

The cross section tool is invoked by selecting a 1D open channel link and clicking on define cross section layout from a popup menu. The user then draws the cross section on the screen as a polyline using as many vertices as appropriate. When the cross section is completed, an $x-y$ plot is displayed. This plot may be printed or exported as a graphics file. 
Additional features of this tool include the ability to automatically generate cross sections at nodes or defined offsets. After they are generated, the cross sections may be graphically edited, printed or exported as a graphics file.

\subsubsection{Presentation of Results}

2D flood models generate a large amount of output. For example, water levels and velocities are stored for every cell in the grid at user defined intervals. Tools are required to enable the monitoring of calculations during the development and calibration phases, and the presentation of results to stakeholders and decision makers. The tools must enable the monitoring of flows, velocities and flood depths and locations of interest and the temporal and spatial trends of these parameters.

The combined $1 \mathrm{D} / 2 \mathrm{D}$ modeling environment uses animations to display model results. The computed values of water depth are displayed as a color coded map. Velocities and flows are displayed as vectors. Their length and/or width can be scaled. The maximum depth occurring at all locations can be highlighted. The animations can be run for the duration of the simulation period or manually stepped through. Animations may save as AVI files for presentation. Some of the presentation techniques are featured in Section 18.4.

\subsection{Case Studies}

The utility of the integrated $1 \mathrm{D} / 2 \mathrm{D}$ modeling capabilities of xpswmm2D is demonstrated in three case studies. The first two are based on work performed for the Fairfield City Council located in the state of New South Wales, Australia (Phillips et al, 2005). The Prospect Creek study compares results from 1D, 2D and 1D/2D models. The Cabramatta study demonstrates the impact of a piped drainage network (1D component) on overland flood depths. The Dubbo study (Smith et al, 2006) demonstrates the ability of xpswmm2D to model overland flow in urban areas.

\subsubsection{Prospect Creek}

The assessment of flooding in the Widemere Road reach of Prospect Creek draws on the outcomes of the previous 1D floodplain modeling using 
xpswmm and 1D/2D modeling using TUFLOW (Cardno Willing, 2004). The 1D xpswmm floodplain model was based on cross sections obtained from previous 1D models and additional survey supplied by Fairfield City Council. The model was calibrated and verified against major floods in 1986 and 1988 and re-calibrated against the January 2001 flood. The 1D/2D TUFLOW model was based on $10 \mathrm{~m} \times 10 \mathrm{~m}$ grid spacing with the Prospect Creek watercourse and all crossings modeled using embedded 1D elements. Crossings and basin outlets were modeled as conduits in combination with weirs. The $1 \mathrm{D} / 2 \mathrm{D}$ TUFLOW model was also calibrated against the January 2001 flood.

For the purposes of this assessment, two further models of the study area were created. The first was a 1D/2D floodplain model using xpswmm2D while the second model was a $2 \mathrm{D}$ model only using TUFLOW. The xpswmm2D model was based on a $10 \mathrm{~m} \times 10 \mathrm{~m}$ grid spacing with the Prospect Creek watercourse and all crossings modeled using embedded 1D elements. The 2D TUFLOW model was also based on a $10 \mathrm{~m} \times 10 \mathrm{~m}$ grid.

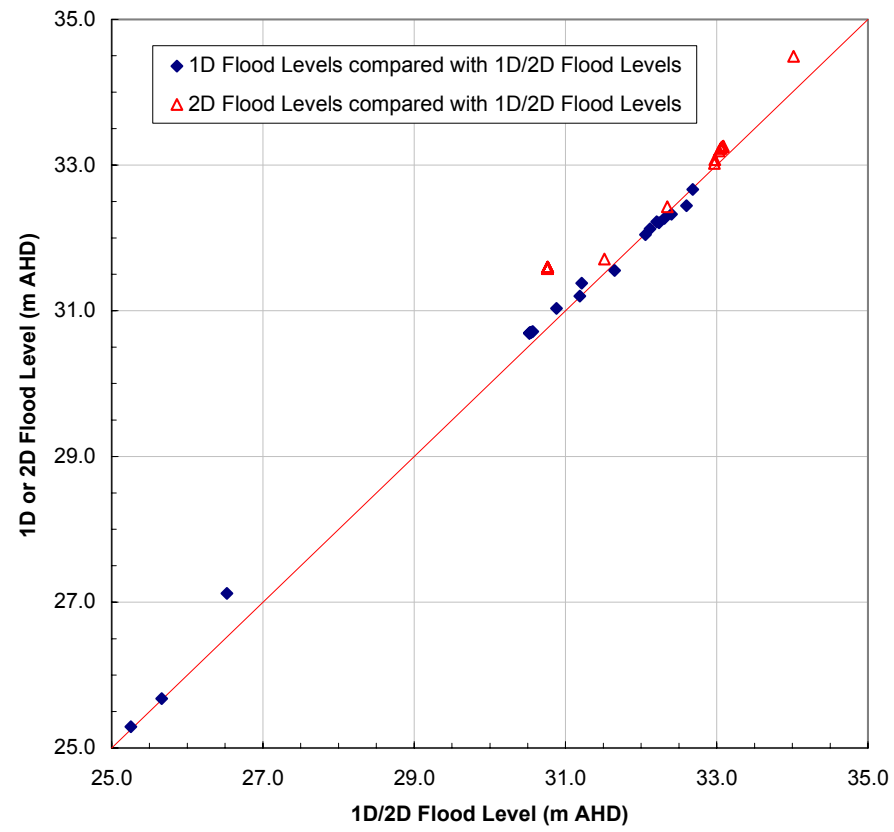

Figure 18.6 Comparison of estimated 1D, 1D/2D and 2D Model $100-y$ ARI Flood Levels in Widemere Road reach of Prospect Creek. 
A comparison of the 100-y ARI flood levels estimated in the Widemere Reach using the 1D xpswmm, xpswmm2D and 2D TUFLOW models is presented in Figure 18.6. The results presented in Figure 18.6 indicate that the 1D and 1D/2D 100-y ARI flood level estimates are in close agreement while the 2D 100 y ARI flood level estimates were typically higher than the 1D/2D 100-y ARI flood levels. This was attributed to the loss of definition of channel sections (typically 6-10 m wide) in the 2D floodplain model. While this problem could be overcome by decreasing the grid spacing this approach would lead to an unmanageably large model for the overall Prospect Creek floodplain (Phillips et al, 2005). It was concluded that these comparisons highlighted the advantages of being able to define narrow watercourses and crossings using $1 \mathrm{D}$ elements and to link these to a $2 \mathrm{D}$ floodplain.

The calculated velocity contours for the xpswmm2D and 2D TUFLOW models are given in Figures 18.7 and 18.8. Examination of these figures shows that the 2D model was not able to accurately describe flow in some of the channel sections.

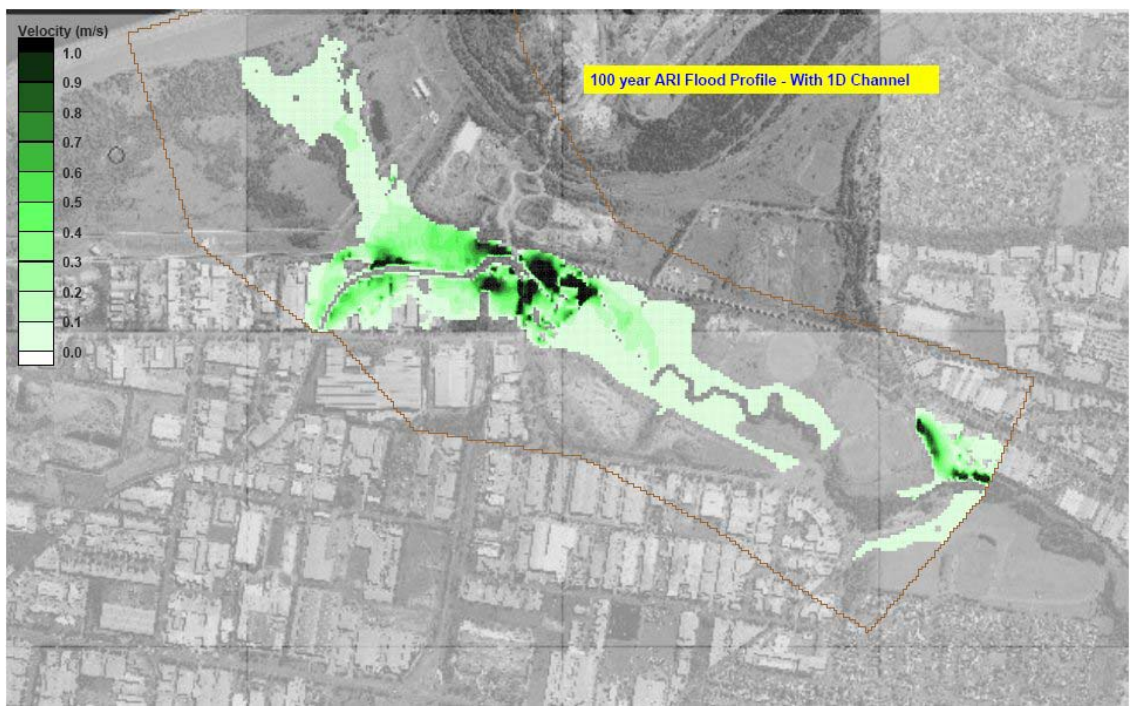

Figure 18.7 1D/2D Model velocity contours in Widemere Road reach of Prospect Creek. 


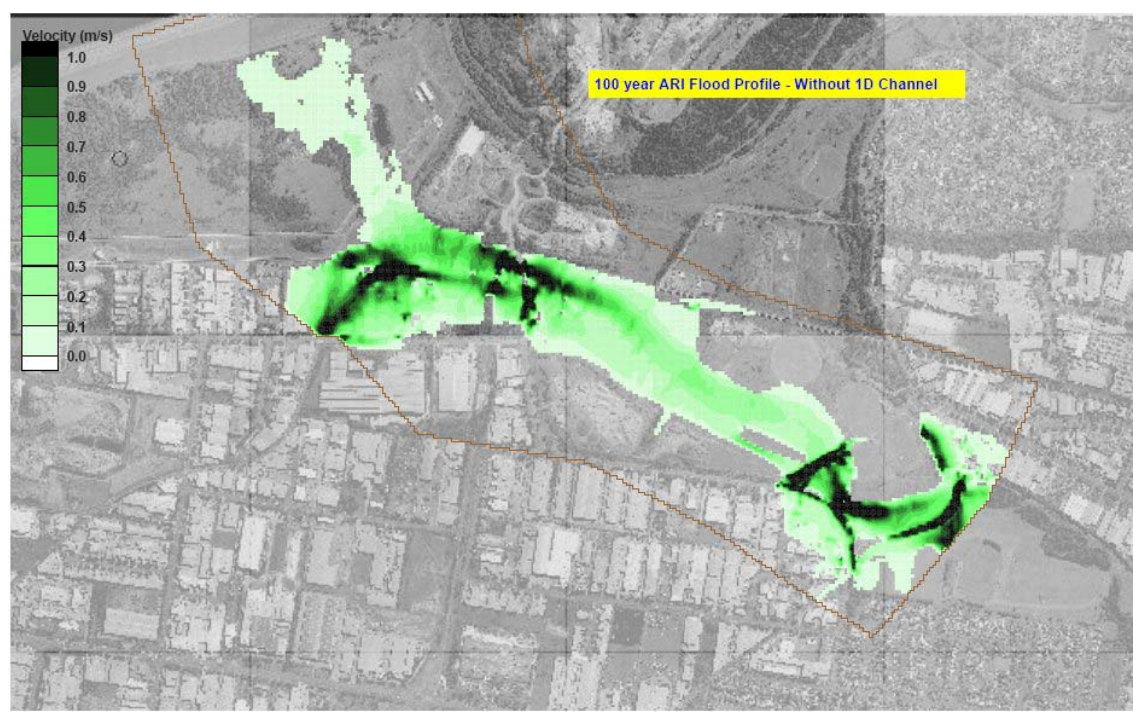

Figure 18.8 2D Model velocity contours in Widemere Road reach of Prospect Creek.

\subsubsection{Cumberland Highway, Cabramatta}

The second case study is of a local drainage subcatchment in the Orphan School Creek catchment that lies within the larger Prospect Creek catchment. The aim of this assessment was to investigate the ability of the xpswmm2D and TUFLOW modeling systems to model the interaction between a complex local piped drainage system and surface overland flows.

The stormwater subcatchment that was selected covers a section of the Cabramatta to Canley Vale local drainage system. Fairfield City Council had previously assessed the adequacy of this local drainage system. This facilitated the provision of detailed information on the local drainage system. The subcatchment is bounded by Cabramatta Road to the south, Lord Street to the west, Gladstone Street to the east, and Derria Street to the north. The total area of the subcatchment is around 165 ha (Phillips et al, 2005).

A dendritic stormwater piped drainage system exists within the catchment. There are over 340 inlet pits in the subcatchment of which 336 pits were modeled. Drainage pipe sizes range from $0.3 \mathrm{~m}$ to $1.8 \mathrm{~m}$ diameter. Details of inlet pit locations, inlet pit capacities, spill levels, pipe sizes, and pipe invert levels were supplied by Fairfield City Council. 
In this assessment, each inlet has its own subcatchment. Over 300 subcatchments were defined and entered into a rainfall runoff model. The catchment model was run to estimate 5-y Annual Return Interval (ARI) design hydrographs. The estimated peak 5-y ARI subcatchment outflow is approximately $40 \mathrm{~m}^{3} / \mathrm{s}$. The drainage system model comprised a $2 \mathrm{D}$ overland flow TUFLOW model and a 1D pipe drainage model. They are coupled together to form a complete $1 \mathrm{D} / 2 \mathrm{D}$ overland flow model. Local runoff hydrographs were entered into the TUFLOW layer where the overland flows were captured by inlets to the piped drainage system (as occurs in the field ie. runoff from roofs and other impervious surfaces are discharged into street gutters where these flows are captured by inlets).

The 2D DTM was generated using aerial laser scanning supplied by Fairfield City Council. A $4 \mathrm{~m} \mathrm{x} 4 \mathrm{~m}$ grid size was adopted for the 2D grid giving over 100,000 elements in the 2D overland flow model. Using typical values the Manning roughness factor of 0.015 was assigned to all the stormwater pipes, while roads and driveways were assigned a factor of 0.02 and houses and lots (including single or double storey dwellings, front and back yards, sheds and fences) were assigned a factor of 0.15 . Inlet and exit losses of 0.5 were adopted for the conduits in the 1D drainage conduits.

Two cases were modeled. The first was the 5-y ARI storm with all inlets to the piped drainage system blocked. This equates to the assumption that has been adopted in a number of previous overland flow studies where it was considered that the capacity of the drainage system is modest in comparison with the estimated overland flows. The second was the 5-y ARI storm with all inlets to the piped drainage system unblocked. It should be noted that the drainage acceptance criterion for local piped drainage systems is a 5-y ARI capacity.

The inundation and overland flow patterns that resulted from these two cases are presented in Figures 18.9 and 18.10. Features of these results include the (Phillips et al, 2005):

- presentation of areas of inundation and of overland flows in a form that is readily understood by the community in comparison with results of previous overland flow studies;

- extensive inundation of properties in a 5-y ARI event albeit with large areas subject to inundation of less than $100 \mathrm{~mm}$;

- additional areas that would be inundated if inlets to the drainage system were substantially or completely blocked (highlighting the need for regular maintenance of drainage pits to ensure their functioning in storm events); and 


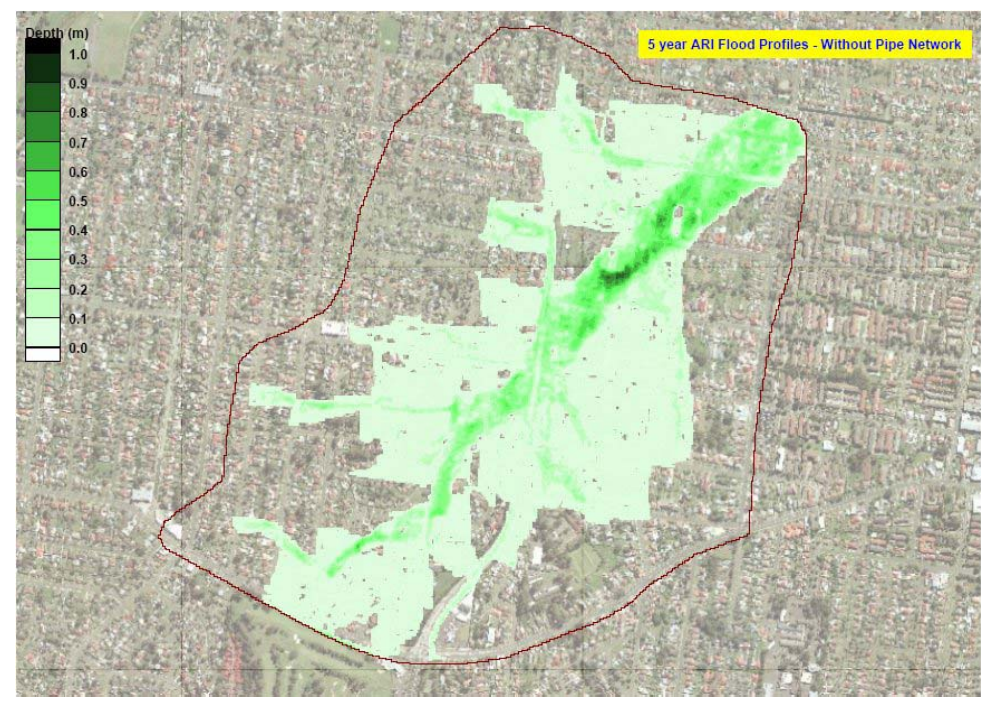

Figure 18.9 Estimated 5-y Annual Return Interval Overland Flows with all inlets blocked.

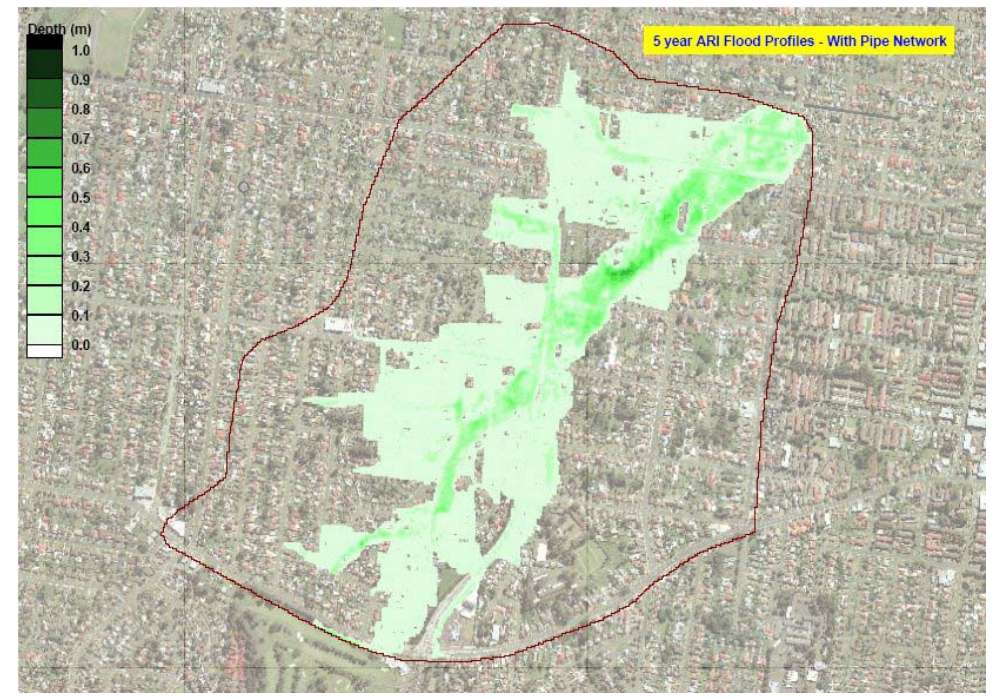

Figure 18.10 Estimated 5-y Annual Return Interval overland flows with all inlets unblocked. 
- conclusion that even if the all drainage inlets are fully unblocked that the piped drainage system does not have a 5-y ARI capacity and that substantial inundation of sections of the major Cumberland Highway and of residential properties would occur.

\subsubsection{City of Dubbo}

Dubbo is a city of 38,000 people located $400 \mathrm{~km}$ north-west of Sydney. The City Council administers both the urban centre of Dubbo and a surrounding rural area in excess of $3,300 \mathrm{~km}^{2}$. The drainage system in Dubbo faces a number of challenges due to the relatively flat grades on stormwater drainage lines and the possibility that overland flows from one local drainage subcatchment may flow into an adjacent subcatchment via the road system.

In the past, flooding investigations in NSW have been typically based on the assembly of hydraulic models of all major watercourses and open channels but not routinely for overland flow paths. The challenge posed by the 2005 NSW Floodplain Development Manual (NSW Government, 2005) is to hydraulically model overland flow paths as well.

The increasing collection of LIDAR data across whole local government areas including the City of Dubbo is providing detailed survey capable of supporting 2D terrain and hydrodynamic modeling and floodplain mapping.

In the xpswmm model, the existing underground drainage system was represented as a network of links and nodes in the 1D layer while overland flows were modeled as an array of cells each having its own elevation and roughness in the $2 \mathrm{D}$ layer. The $1 \mathrm{D}$ and $2 \mathrm{D}$ layers were connected at inlets to allow overland flows to enter the piped drainage system and for the piped drainage system to surcharge onto roads as appropriate (Smith et al, 2006).

One flood prone area is the intersection of Church and Brisbane streets. Model results at this location during the 100-y storm under existing conditions (see Figure 18.11) and for concept augmentation works are shown in Figure 18.12. In Figure 19.11, note that the overland flow results in flooding as deep as $0.4 \mathrm{~m}$ along both sides of Brisbane Street and along Church Street. Figure 19.12 shows that the augmentation project mitigates but does not eliminate the flooding on Brisbane Street. 


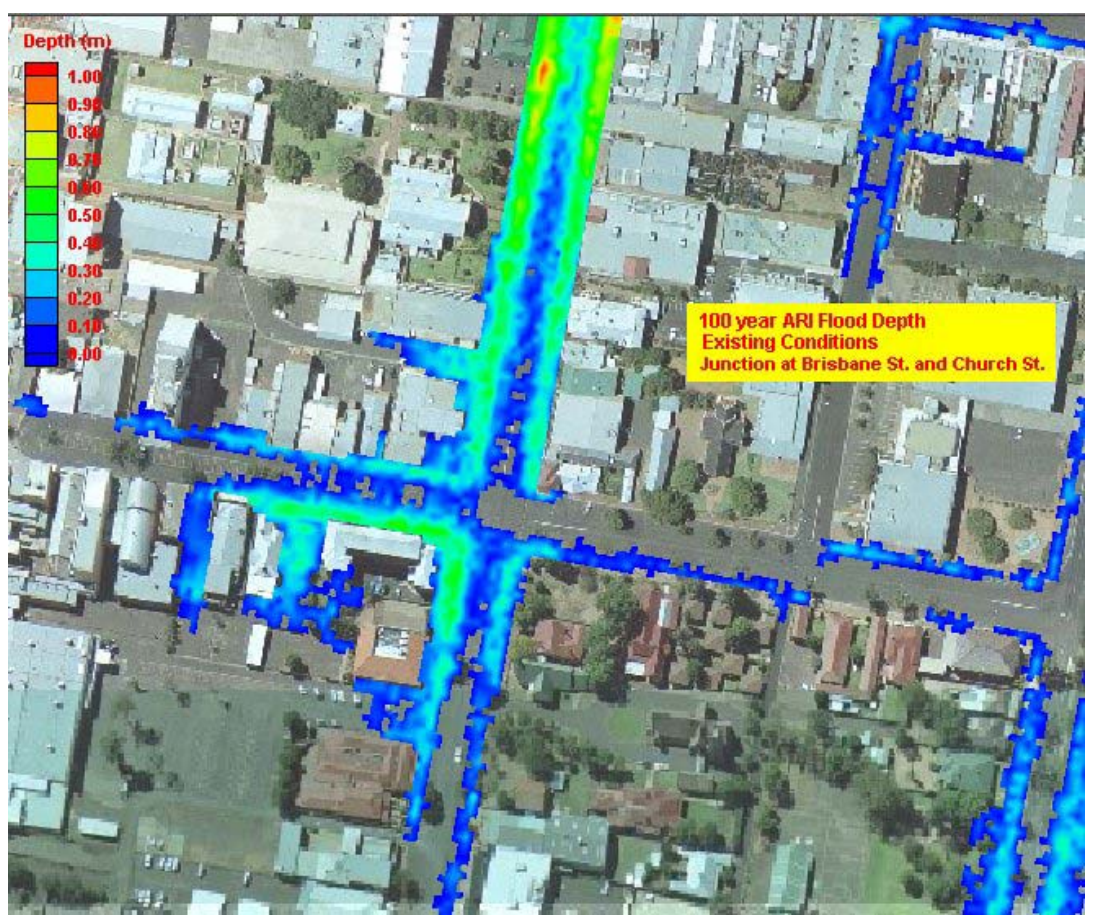

Figure 18.11 Estimated 100-y ARI flood depths and extents at Brisbane Street \& Church Street intersection - existing conditions.

The results of the study showed that:

- the combined $1 \mathrm{D} / 2 \mathrm{D}$ modeling capabilities in the xpswmm2D package offers Dubbo City Council new opportunities to undertake more detailed investigations of urban drainage systems and of overland flows; and

- the modeling completed to date has highlighted the interconnection of local drainage subcatchments.

\subsection{Summary and Conclusions}

Based on the analysis and results presented in this chapter it is concluded that, although 1D steady and unsteady flow models are the dominant tools for the design and analysis of drainage systems and for flood mapping, 2D 


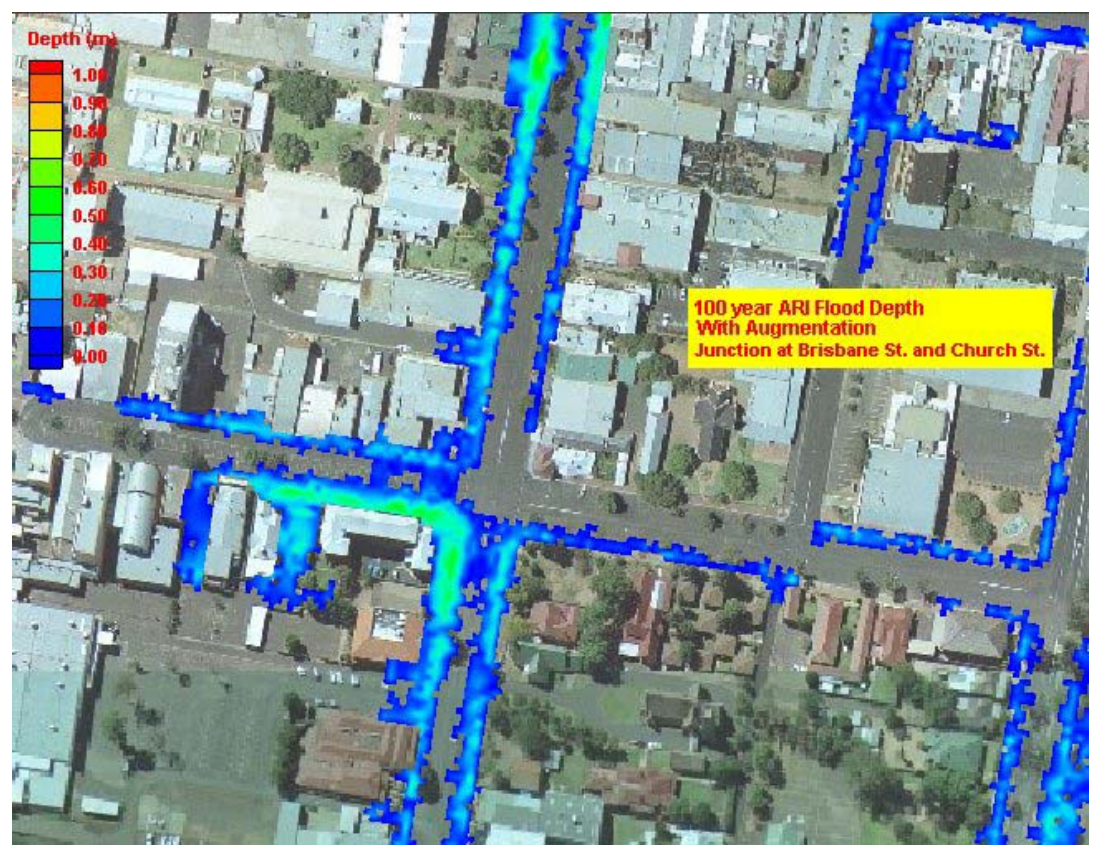

Figure 18.12 Estimated 100-y ARI flood depths and extents at Brisbane Street \& Church Street intersection - with concept augmentation works.

packages are better able to model complex flow patterns on rural, urbanizing or urban floodplains. 1D/2D simulations offer advantages over quasi $2 \mathrm{D}$ simulations by:

- removing the constraint that all overbank floodplain flows are approximated by $1 \mathrm{D}$ links; and

- enhancing the interaction between conduit systems and surface systems under conditions of surcharge and overflow.

The consideration of extreme flooding events and resulting flood damages in urban areas and the availability of aerial laser scanning is leading to the growing adoption of 2D models for urban flooding investigations. In addition, the presentation of modeling results (static or animated) in 2D and/or 3D are better understood by a non-technical audience than traditional methods. xpswmm2D offers new opportunities to 
undertake $1 \mathrm{D}, 1 \mathrm{D} / 2 \mathrm{D}$ or $2 \mathrm{D}$ assessments of mainstream flooding as well as local flooding and overland flows.

Although the results of the case studies presented here have not been verified with measurements from flood events, the work demonstrates the features and the power of 1D/2D linked hydrodynamic models and their utility to the management of drainage systems.

\section{Acknowledgments}

The support of Fairfield City Council and Dubbo City Council for the assessments described herein through the provision of extensive ALS data and detailed drainage system data is gratefully acknowledged. The views expressed in this chapter are those of the authors and are not necessarily the views of Fairfield City Council or Dubbo City Council.

\section{References}

Bellomo, D., 2004, Policy for Accepting Numerical Models for Us in the NFIP, Memorandum, August 16.

Charteris, A.B., Syme, W.J. and Walden, W.J., 2001, Urban Modelling and Mapping 2D or not $2 \mathrm{D}$.

Depue, M., 2005, Georgia Takes Flood Mapping by Storm, Stormwater, 6(7), 60.

Haestad Methods, Dyhouse, G., Hatchett, J., Benn, J., 2003. Floodplain Modeling Using HEC-RAS, Haestad Press.

NSW Government (2005) "Floodplain Development Manual, the management of flood liable land", April, Sydney.

Office of Inspector General, Department of Homeland Security, 2005. Challenges in FEMA's Flood Map Modernization Program, OIG-05-44.

Phillips, B.C., Yu, S., Thompson, G.R., and de Silva, N.. 2005. 1D and 2D Modelling of Urban Drainage Systems using XP-SWMM and TUFLOW. Proceedings, $10^{\text {th }}$ International Conference on Urban Drainage, Copenhagen, Denmark, 21-26 August 2005.

Smith, J., Phillips, B.C.and Yu, S. 2006, Modelling Overland Flows and Drainage Augmentation in Dubbo, Proceedings, $46^{\text {th }}$ Floodplain Management Authorities Conference, 1-2 March 2006, Lismore, Australia.

Syme, W.J., Pinnell, M.G., and Wicks, J.M. 2004, Modeling Flood Inundation of Urban Ares in the UK Using 2D/1D Hydraulic Models, Proceedings, $8^{\text {th }}$ National Conference on Hydraulics in Water Engineering, The Institution of Engineers, Australia.

Tate. E.C., Maidment, D.R., Olivera, F., and Anderson, D.J., 2002, Creating a Terrain Model for Floodplain Mapping, J. Hydrologic Engineering 7 (2) 100. 
WBM Oceanics (2005) "TUFLOW (and ESTRY) User Manual - GIS Based 2D/1D

Hydrodynamic Modelling”, User Manual, May, Brisbane. 